\title{
Expression of MUC1, MUC2, MUC5AC and MUC5B in Mucinous Lesions of the Breast
}

\author{
Dokyung Kim $^{a}$ Woo-Hee Jung ${ }^{\mathrm{b}}$ Ja Seung Koo ${ }^{\mathrm{b}}$ \\ a Department of Pathology, Ajou University Medical Center, Suwon, and ${ }^{\text {b}}$ Department of Pathology, Yonsei \\ University Health System, Seoul, Korea
}

\section{Key Words}

Breast $\cdot$ Mucin $\cdot$ Mucinous carcinoma $\cdot$ Mucocele-like

lesion $\cdot$ Solid papillary carcinoma

\begin{abstract}
Objective: The purpose of this study was to investigate the expression of MUC1, MUC2, MUC5AC and MUC5B in breast mucinous lesions. Methods: Immunohistochemical staining of MUC1, MUC2, MUC5AC, MUC5B and synaptophysin was performed in 78 cases of mucinous carcinoma (MC), 36 cases of mucocele-like lesions (MLL) and 13 cases of solid papillary carcinoma (SPC). MC was classified as type A or type B and MLL was classified as MLL, MLL with atypical ductal hyperplasia and MLL with ductal carcinoma in situ. Results: MUC1 was expressed in MC type $A$ and MLL with luminal/apical pattern, while MC type $B$ and SPC showed membrano-cytoplasmic expression of MUC1 $(p<0.001)$. A luminal/apical or luminal/apical + cytoplasmic pattern of MUC2 expression was observed in MC type A, while MC type B and SPC showed membrano-cytoplasmic MUC2 expression $(p<0.001)$. On MUC5B staining, MC type A and MLL were negative, while $M C$ type $B$ and SPC showed membrano-cytoplasmic expres$\operatorname{sion}(p=0.011)$. The positive rate for synaptophysin was higher in MC type B and SPC than in MLL and MC type $A$ ( $p=$ 0.001). Conclusions: Similar MUC phenotypes were observed between MLL and MC type A and between MC type $B$ and SPC.

Copyright $\odot 2012$ S. Karger AG, Basel
\end{abstract}

\section{Introduction}

Mucocele-like lesions (MLL) and mucinous carcinoma (MC) are two ends of the pathological spectrum of breast mucinous lesions. MLL with atypical ductal hyperplasia $(\mathrm{ADH})$ and MLL with ductal carcinoma in situ (DCIS) are in the middle of this spectrum [1]. Mucinous lesions in the breast are uncommon. A report of breast core biopsies showed that mucinous lesions are found only in $0.51 \%$ of all breast lesions [2]. The following characteristics support the possibility that MLL are a precursor lesion of MC. First, MC accompanies MLL $[1,3]$. Second, there is a high probability of accompanying MC in cases of MLL with ADH and MLL with DCIS $[1,3,4]$. Lastly, the peak age of MLL with ADH is 10 years younger than MC in screen-detected MLL [4]. One of the important components of breast mucinous lesions is mucin, a high molecular weight glycoprotein with oligosaccharides attached to serine or threonine residues of a mucin core protein backbone by $\mathrm{O}$-glycosidic linkages. Mucin is largely classified into two groups: membrane-bound mucin, such as MUC1, MUC3A, MUC4, MUC12, MUC13 and MUC17, and gel-forming mucin, such as MUC2, MUC5AC, MUC5B and MUC6 [5]. An earlier study reported that invasive ductal carcinoma (IDC) exhibits MUC1, MUC3 and MUC4 expression [6]. MUC1 and MUC3 are also reportedly potential prognostic indicators of IDC [6]. In contrast, the expression of MUC2 and

\section{KARGER}

Fax +4161306 1234 E-Mail karger@karger.ch www.karger.com
(C) 2012 S. Karger AG, Base 1015-2008/12/0793-0144\$38.00/0

Accessible online at: www.karger.com/pat
J.S. Koo

Department of Pathology, Yonsei University College of Medicine, Severance Hospital 250 Seongsanno, Seodaemun-gu

Seoul 120-752 (Korea)

Tel. +82 22228 1772, E-Mail kjs1976@yuhs.ac 
Table 1. Patient characteristics

\begin{tabular}{|c|c|c|c|c|}
\hline Parameter & $\begin{array}{l}\text { Total } \\
(\mathrm{n}=78)\end{array}$ & $\begin{array}{l}\text { Type A } \\
(\mathrm{n}=58)\end{array}$ & $\begin{array}{l}\text { Type B } \\
(\mathrm{n}=20)\end{array}$ & $\mathrm{p}$ value \\
\hline Mean tumor size $\pm \mathrm{SD}, \mathrm{cm}$ & $2.2 \pm 1.2$ & $2.2 \pm 1.3$ & $2.0 \pm 0.5$ & 0.415 \\
\hline Age & & & & 0.032 \\
\hline$<50$ years & $47(60.3)$ & $39(67.2)$ & $8(40.0)$ & \\
\hline$\geq 50$ years & $31(39.7)$ & $19(32.8)$ & $12(60.0)$ & \\
\hline Histologic grade & & & & 0.265 \\
\hline I & $68(87.2)$ & $52(90.0)$ & $16(80.0)$ & \\
\hline II & $10(12.8)$ & $6(10.0)$ & $4(20.0)$ & \\
\hline III & $0(0.0)$ & $0(0.0)$ & $0(0.0)$ & \\
\hline \multicolumn{5}{|l|}{ Nuclear grade } \\
\hline 1 & $59(75.6)$ & $43(74.1)$ & $16(80.0)$ & \\
\hline 2 & $19(24.4)$ & $15(25.9)$ & $4(20.0)$ & \\
\hline 3 & $0(0.0)$ & $0(0.0)$ & $0(0.0)$ & \\
\hline Lymph node metastasis & $16(20.5)$ & $13(22.4)$ & $3(15.0)$ & 0.479 \\
\hline Estrogen receptor & & & & 0.471 \\
\hline Positive & $71(91.0)$ & $52(90.0)$ & $19(95.0)$ & \\
\hline Negative & $7(9.0)$ & $6(10.0)$ & $1(5.0)$ & \\
\hline Progesterone receptor & & & & 0.939 \\
\hline Positive & $58(74.4)$ & $43(74.1)$ & $15(75.0)$ & \\
\hline Negative & $20(25.6)$ & $15(25.9)$ & $5(25.0)$ & \\
\hline HER-2 status (IHC) & & & & 0.397 \\
\hline Negative $(0,1+)$ & $66(84.6)$ & $48(82.8)$ & $18(90.0)$ & \\
\hline Equivocal $(2+)$ & $7(9.0)$ & $5(8.6)$ & $2(10.0)$ & \\
\hline Positive $(3+)$ & $5(6.4)$ & $5(8.6)$ & $0(0.0)$ & \\
\hline HER-2 amplification (FISH) & $5(6.4)$ & $5(8.6)$ & $0(0.0)$ & 0.175 \\
\hline
\end{tabular}

Figures in parentheses are percentages. FISH = Fluorescence in situ hybridization.

MUC5 is higher in MC than in IDC [7]. Pure MC is found in $2 \%$ of all breast cancers and shows less frequent lymph node metastasis and a more favorable prognosis [8-10]. Capella et al. [11] classified pure breast MC into two main types according to its structural and cytological features: type A (paucicellular), the classical variant with a large amount of extracellular mucin, and type B (hypercellular), a hypercellular variant with less mucin and often with neuroendocrine differentiation. In addition to MLL, $\mathrm{MC}$ and solid papillary carcinoma (SPC) can be included in breast mucinous lesions. Nine percent of SPCs secrete extravasated mucin, and SPCs are occasionally combined with MC [12]. Furthermore, the neuroendocrine features and cellular solid nest architecture similar to MC type B are observed in SPCs, which supports the hypothesis that SPC is a precursor of MC $[12,13]$. Therefore, there could be similarities or differences in MUC protein expression among breast mucinous lesions. However, no study has been performed to clearly demonstrate such similarities or differences.

MUC Expression in Mucinous Lesions
The purpose of this research was to investigate the expression of various MUCs in breast mucinous lesions and to find out the similarities or differences of MUC phenotypes in breast mucinous lesions.

\section{Materials and Methods}

Patient Selection and Clinicopathological Analysis

Among a total of 78 cases diagnosed with MC, 49 cases were included in this study. The selected cases were 13 cases of SPC and 36 cases of MLL diagnosed upon breast surgery or tissue excision at the Severance Hospital between January 1996 and December 2009. Cases of mixed MC and IDC were excluded. The Institutional Review Board of Yonsei University Severance Hospital approved this study. All cases included were independently and retrospectively reviewed by experienced breast pathologists (J.S.K. and W.-H.J.). Histologic parameters were evaluated from H\&Estained slides. Histological grade was assessed using the Nottingham grading system, and the nuclear grade was evaluated according to modified Black's nuclear grade ( 1 = low grade, 2 = intermediate grade, and $3=$ high grade) [14]. MC was classified into type 
Table 2. MUC1, MUC2, MUC5AC and MUC5B expression in breast mucinous lesions

\begin{tabular}{|c|c|c|c|c|c|}
\hline \multirow[t]{2}{*}{ Parameter } & \multicolumn{2}{|l|}{ MC } & \multirow{2}{*}{$\begin{array}{l}\text { MLL } \\
(\mathrm{n}=36)\end{array}$} & \multirow{2}{*}{$\begin{array}{l}\text { SPC } \\
(n=13)\end{array}$} & \multirow[t]{2}{*}{$\mathrm{p}$ value } \\
\hline & $\begin{array}{l}\text { type A } \\
(\mathrm{n}=58)\end{array}$ & $\begin{array}{l}\text { type B } \\
(n=20)\end{array}$ & & & \\
\hline MUC1 & & & & & 0.000 \\
\hline Negative & $0(0.0)$ & $0(0.0)$ & $0(0.0)$ & $0(0.0)$ & \\
\hline Luminal/apical & $51(87.9)$ & $4(20.0)$ & $23(63.9)$ & $0(0.0)$ & \\
\hline Luminal/apical + cytoplasmic & $5(8.6)$ & $1(5.0)$ & $13(36.1)$ & $0(0.0)$ & \\
\hline Membrano-cytoplasmic & $2(3.4)$ & $15(75.0)$ & $0(0.0)$ & $13(100.0)$ & \\
\hline MUC2 & & & & & 0.000 \\
\hline Negative & $5(8.6)$ & $1(5.0)$ & $18(50.0)$ & $7(53.8)$ & \\
\hline Luminal/apical & $27(46.6)$ & $0(0.0)$ & $1(2.8)$ & $0(0.0)$ & \\
\hline Luminal/apical + cytoplasmic & $21(36.2)$ & $1(5.0)$ & $8(22.2)$ & $0(0.0)$ & \\
\hline Membrano-cytoplasmic & $5(8.6)$ & $18(90.0)$ & $9(25.0)$ & $6(46.2)$ & \\
\hline MUC5AC & & & & & 0.586 \\
\hline Negative & $53(91.4)$ & $19(95.0)$ & $36(100.0)$ & $13(100.0)$ & \\
\hline Luminal/apical & $0(0.0)$ & $0(0.0)$ & $0(0.0)$ & $0(0.0)$ & \\
\hline Luminal/apical + cytoplasmic & $1(1.7)$ & $0(0.0)$ & $0(0.0)$ & $0(0.0)$ & \\
\hline Membrano-cytoplasmic & $4(6.9)$ & $1(5.0)$ & $0(0.0)$ & $0(0.0)$ & \\
\hline MUC5B & & & & & 0.011 \\
\hline Negative & $46(79.3)$ & $12(60.0)$ & $28(77.8)$ & $7(53.8)$ & \\
\hline Luminal/apical & $1(1.7)$ & $0(0.0)$ & $4(11.1)$ & $0(0.0)$ & \\
\hline Luminal/apical + cytoplasmic & $0(0.0)$ & $0(0.0)$ & $0(0.0)$ & $0(0.0)$ & \\
\hline Membrano-cytoplasmic & $11(19.0)$ & $8(40.0)$ & $4(11.1)$ & $6(46.2)$ & \\
\hline Synaptophysin & & & & & 0.001 \\
\hline Negative & $55(94.8)$ & $14(70.0)$ & $33(91.7)$ & $8(61.5)$ & \\
\hline Positive & $3(5.2)$ & $6(30.0)$ & $3(8.3)$ & $5(38.5)$ & \\
\hline
\end{tabular}

Figures in parentheses are percentages.

A and type B according to the criteria suggested by Capella et al. [11]. Type A (paucicellular) is the classical variant with a large amount of extracellular mucin and type B (hypercellular) is a hypercellular variant with less mucin and often with neuroendocrine differentiation [11].

\section{Immunohistochemical Staining}

Immunostaining was performed using formalin-fixed, paraffin-embedded tissue sections. Immunohistochemical (IHC) staining was performed for MUC1 (BC-2, 1:100; Abcam, Cambridge, UK), MUC2 (Ccp58, 1:200; NovoCastra, Newcastle, UK), MUC5B (19-4E, 1:100; Abcam), MUC5AC (CLH2, 1:100; NovoCastra) and synaptophysin (SY38, 1:10; Abcam). Briefly, 5- $\mu \mathrm{m}-$ thick sections were obtained with a microtome, transferred onto adhesive slides and dried at $62^{\circ} \mathrm{C}$ for $30 \mathrm{~min}$. After incubation with primary antibodies, immunodetection was performed by incubation of the specimens with biotinylated anti-mouse immunoglobulin followed by peroxidase-labeled streptavidin from a labeled streptavidin biotin kit with 3,3'-diaminobenzidine chromogen as the substrate. The primary antibody incubation step was omitted in the negative control. The slides were counterstained with Harris hematoxylin.
Interpretation of IHC Staining Results

All IHC markers were assessed by light microscopy. MUC positivity was indicated when $>10 \%$ of the tumor or lesion expressed the MUC of interest. In addition, subcellular localization of MUC expression was assigned as follows: luminal/apical, luminal/api$\mathrm{cal}+$ cytoplasmic, and membrano-cytoplasmic expressions. IHC stain of synaptophysin was considered as positive when $>10 \%$ of the tumor or lesion was expressed.

\section{Statistical Analysis}

Data were statistically analyzed using SPSS for Windows, version 12.0 (SPSS Inc., Chicago, Ill., USA). Student's t test and Fisher's exact test were used to determine the differences between groups with respect to continuous and categorical variables, respectively. Statistical significance was assumed when $\mathrm{p}<0.05$.

\section{Results}

\section{Characteristics}

The clinicopathological features of MC from 78 patients are shown in table 1 . Fifty-eight (74.4\%) cases be- 

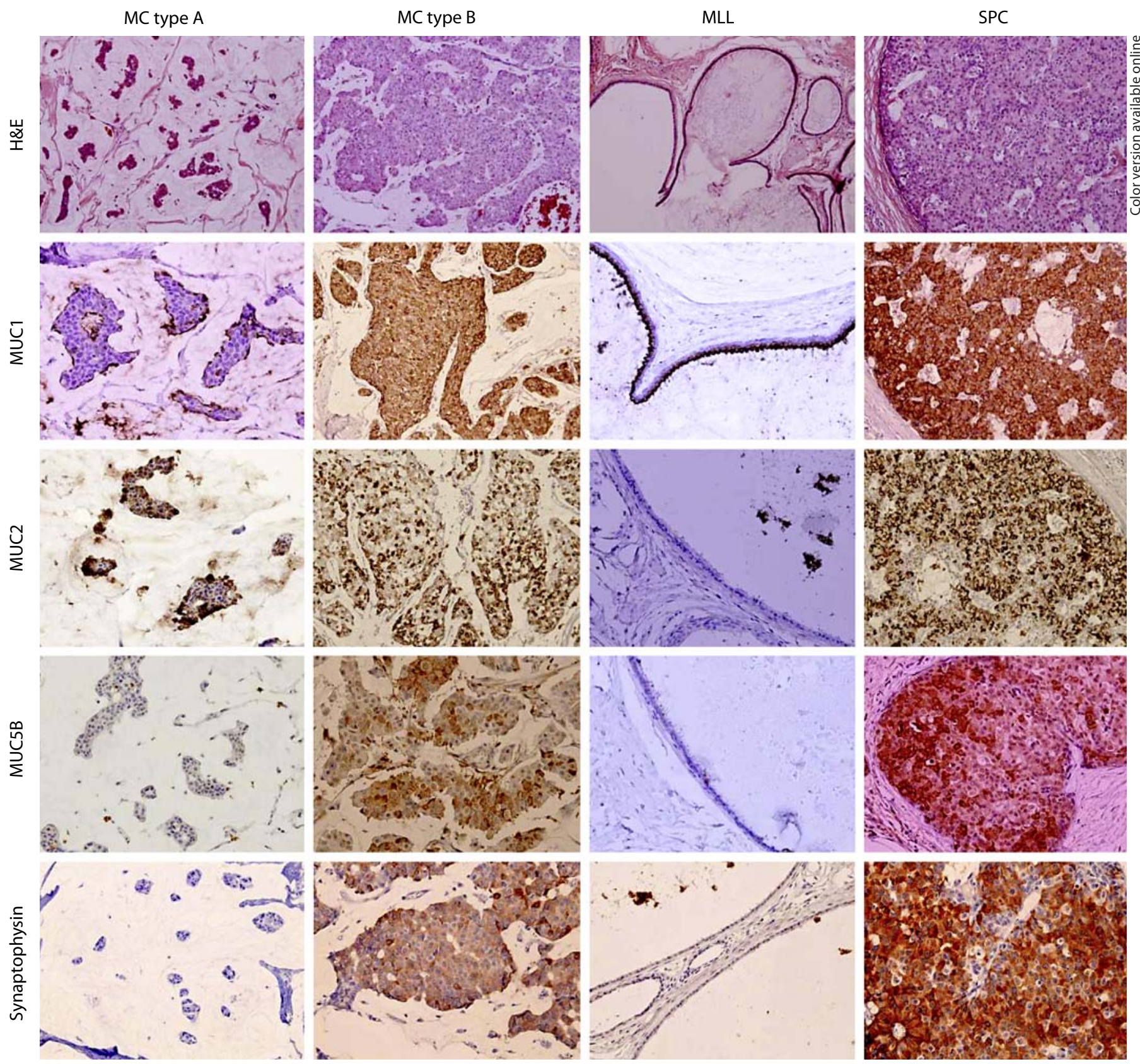

Fig. 1. MUC1, MUC2, MUC5AC and MUC5B expression in breast mucinous lesions. MC type A and MLL showed luminal/apical MUC1 expression and were MUC5B negative. However, MC type B and SPC demonstrated a membrano-cytoplasmic expression pattern of MUC1 and MUC5B and cytoplasmic expression of synaptophysin.

longed to type A and 20 cases (25.6\%) were type B. Type A appeared more often in women $<50$ years old than type B $(p=0.032)$. Five cases $(6.4 \%)$ of type A MC showed HER-2 overexpression and amplification.

MUC Expression in Mucinous Lesions
MUC1, MUC2, MUC5AC and MUC5B Expression in

Breast Mucinous Lesions

The expression of MUC1, MUC2, MUC5AC and MUC5B in breast mucinous lesions is summarized in table 2 and figure 1 . All breast mucinous lesions expressed

Pathobiology 2012;79:144-153 

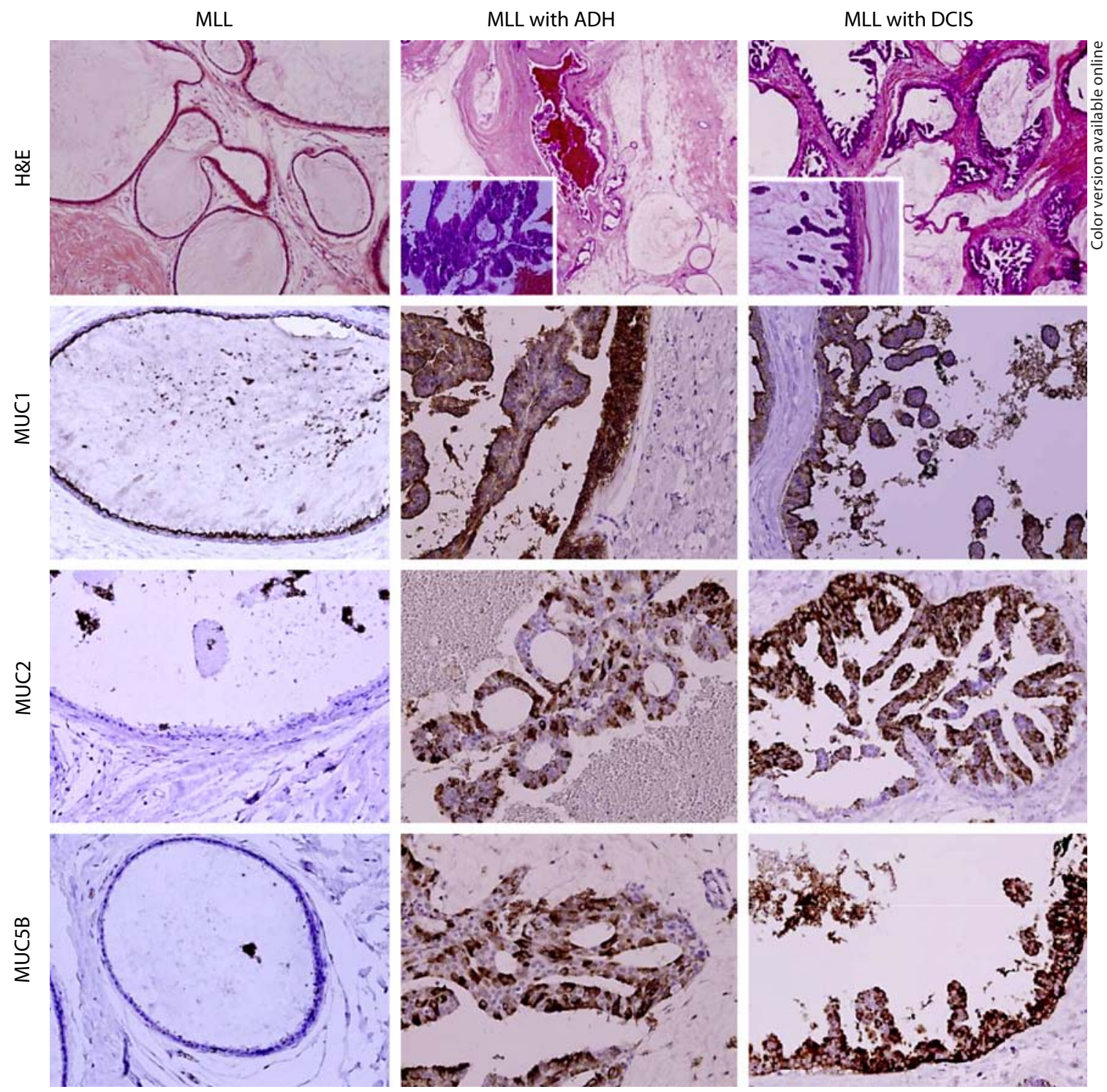

Fig. 2. MUC1, MUC2, MUC5AC and MUC5B expression in MLL. Simple MLL were negative in terms of MUC2 and MUC5B expression, but MLL with ADH/DCIS demonstrated a membrano-cytoplasmic expression pattern of MUC2 and MUC5B.

MUC1. Luminal/atypical expression of MUC1 was observed in $87.9 \%$ of MC type A and in $63.9 \%$ of MLL cases, while $75 \%$ of MC type B and all SPC cases showed membrano-cytoplasmic expression $(\mathrm{p}<0.000)$. With respect to MUC2 staining, $82.8 \%$ of MC type A cases had either a luminal/apical or a luminal/apical + cytoplasmic pattern, while $90.0 \%$ of MC type B and $46.2 \%$ of SPC specimens showed a membrano-cytoplasmic pattern ( $p<0.000)$. A total of $79.3 \%$ of MC type A and $77.8 \%$ of MLL cases were negative for MUC5B expression, while
$40.0 \%$ of MC type B and $46.2 \%$ of SPC cases showed membrano-cytoplasmic expression of MUC5B ( $\mathrm{p}=$ 0.011 ). The positive rate for synaptophysin was higher in MC type B and SPC than in MLL and MC type A ( $\mathrm{p}=$ $0.001)$.

The expression patterns for MUC1, MUC2, MUC5AC and MUC5B in the MLL specimens are shown in table 3. Sixteen (44.4\%) cases were MLL, 17 (47.2\%) cases were MLL with ADH, and 3 (8.3\%) cases were MLL with DCIS. Both MLL and MLL with DCIS cases showed luminal/ 
Table 3. MUC1, MUC2, MUC5AC and MUC5B expression in MLL

\begin{tabular}{|c|c|c|c|c|}
\hline Parameter & $\begin{array}{l}\text { MLL } \\
(n=16)\end{array}$ & $\begin{array}{l}\text { MLL } \\
\text { with ADH } \\
(\mathrm{n}=17)\end{array}$ & $\begin{array}{l}\text { MLL } \\
\text { with DCIS } \\
(\mathrm{n}=3)\end{array}$ & $\mathrm{p}$ value \\
\hline MUC1 & & & & 0.000 \\
\hline Negative & $0(0.0)$ & $0(0.0)$ & $0(0.0)$ & \\
\hline Luminal/apical & $15(100.0)$ & $5(29.4)$ & $3(100.0)$ & \\
\hline Luminal/apical + cytoplasmic & $0(0.0)$ & $12(70.6)$ & $0(0.0)$ & \\
\hline Membrano-cytoplasmic & $0(0.0)$ & $0(0.0)$ & $0(0.0)$ & \\
\hline MUC2 & & & & 0.098 \\
\hline Negative & $12(75.0)$ & $6(35.3)$ & $0(0.0)$ & \\
\hline Luminal/apical & $0(0.0)$ & $1(5.9)$ & $0(0.0)$ & \\
\hline Luminal/apical +cytoplasmic & $1(6.3)$ & $5(29.4)$ & $2(66.7)$ & \\
\hline Membrano-cytoplasmic & $3(18.8)$ & $5(29.4)$ & $1(33.3)$ & \\
\hline MUC5AC & & & & $\mathrm{n} / \mathrm{a}$ \\
\hline Negative & $16(100.0)$ & $17(100.0)$ & $3(100.0)$ & \\
\hline MUC5B & & & & 0.022 \\
\hline Negative & $14(87.5)$ & $13(76.4)$ & $1(33.3)$ & \\
\hline Luminal/apical & $2(12.5)$ & $2(11.8)$ & $0(0.0)$ & \\
\hline Luminal/apical + cytoplasmic & $0(0.0)$ & $0(0.0)$ & $0(0.0)$ & \\
\hline Membrano-cytoplasmic & $0(0.0)$ & $2(11.8)$ & $2(66.7)$ & \\
\hline Synaptophysin & & & & 0.124 \\
\hline Negative & $16(100.0)$ & 15 (88.2) & $2(66.7)$ & \\
\hline Positive & $0(0.0)$ & $2(11.8)$ & $1(33.3)$ & \\
\hline
\end{tabular}

Figures in parentheses are percentages. $\mathrm{n} / \mathrm{a}=$ Not assessed.

apical MUC1 expression, while $70.6 \%$ of MLL with ADH cases showed a luminal/apical + cytoplasmic expression pattern $(p=0.001)$. Cases of MLL with ADH showed a luminal/apical expression pattern in the $\mathrm{ADH}$ area and a luminal/apical + cytoplasmic expression pattern in the MLL area (fig. 2). The cases of MLL with ADH and MLL with DCIS showed luminal/apical + cytoplasmic or membrano-cytoplasmic MUC2 expression, while most MLL cases were MUC2 negative ( $\mathrm{p}=0.098$; fig. 2). MLL specimens were mostly negative with respect to MUC5B staining, but $11.8 \%$ of MLL with ADH and $66.7 \%$ of MLL with DCIS cases showed membrano-cytoplasmic MUC5B expression ( $\mathrm{p}=0.022$; fig. 2 ).

\section{Impact of MUC1, MUC2, MUC5AC and MUC5B}

Expression on Clinicopathological Factors in $M C$

Table 4 illustrates the correlation between MUC1, MUC2, MUC5AC and MUC5B expression and clinicopathologic factors in MC. In MUC1 and MUC2 staining, luminal/apical or luminal/apical + cytoplasmic expression patterns were related to MC type A. Membrano-cytoplasmic expression of MUC1 and MUC2 was related to
MC type B ( $\mathrm{p}=0.000)$. MUC2-negative MCs were larger in size than MUC2-positive MCs ( $\mathrm{p}=0.011)$, and membrano-cytoplasmic MUC2 expression was related to higher histological grade $(\mathrm{p}=0.007)$.

\section{Discussion}

The purpose of this study was to investigate the expression of MUC1, MUC2, MUC5AC and MUC5B in breast mucinous lesions. MUC1 was expressed in all MCs, and this result is consistent with earlier studies that reported MUC1 expression in $90-100 \%$ of IDCs [6, 7] and in $65-100 \%$ of MCs depending on the type of antibody used for IHC analysis [7]. In this study, the subcellular localization of MUC1 expression was mainly luminal/apical in MC type A cases and membrano-cytoplasmic in MC type B cases $(p<0.000)$. MC type A and type $\mathrm{B}$ cases show several different characteristics. MC type $\mathrm{B}$ has a higher ratio of tumor cells to mucin, a solid and trabecular growth pattern and neuroendocrine differentiation [11]. A previous study reported the different fea- 
Table 4. Correlation of MUC1, MUC2, MUC5AC and MUC5B expression with clinicopathologic factors in MC

\begin{tabular}{|c|c|c|c|c|c|c|c|}
\hline & $\begin{array}{l}\text { LA or LAC } \\
(\mathrm{n}=61)\end{array}$ & $\begin{array}{l}\text { CM } \\
(n=17)\end{array}$ & $\mathrm{p}$ value & $\begin{array}{l}\text { no expression } \\
(\mathrm{n}=6)\end{array}$ & $\begin{array}{l}\text { LA or LAC } \\
(\mathrm{n}=49)\end{array}$ & $\begin{array}{l}\text { CM } \\
(n=23)\end{array}$ & $\mathrm{p}$ value \\
\hline Mean tumor size $\pm \mathrm{SD}, \mathrm{cm}$ & $2.3 \pm 1.3$ & $1.9 \pm 0.5$ & 0.316 & $3.6 \pm 3.1$ & $2.1 \pm 0.9$ & $2.0 \pm 0.5$ & 0.011 \\
\hline Histologic type & & & 0.000 & & & & 0.000 \\
\hline Age & & & 0.069 & & & & 0.102 \\
\hline$<50$ years & 40 & 7 & & 5 & 32 & 10 & \\
\hline$\geq 50$ years & 21 & 10 & & 1 & 17 & 13 & \\
\hline Histologic grade & & & 0.501 & & & & 0.007 \\
\hline $\mathrm{I}$ & 54 & 14 & & 3 & 46 & 19 & \\
\hline 2 & 16 & 3 & & 3 & 11 & 5 & \\
\hline Lymph node metastasis & 15 & 1 & 0.091 & 3 & 11 & 2 & 0.071 \\
\hline Estrogen receptor & & & 0.614 & & & & 0.569 \\
\hline Positive & 55 & 16 & & 5 & 44 & 22 & \\
\hline Negative & 6 & 1 & & 1 & 5 & 1 & \\
\hline Progesterone receptor & & & 0.393 & & & & 0.057 \\
\hline Positive & 44 & 14 & & 2 & 38 & 18 & \\
\hline Negative & 17 & 3 & & 4 & 11 & 5 & \\
\hline HER-2 status (IHC) & & & 0.446 & & & & 0.001 \\
\hline Negative $(0,1+)$ & 51 & 15 & & 2 & 44 & 20 & \\
\hline
\end{tabular}

tures of MUC1 subcellular localization in breast cancer. It reported that apical cellular MUC1 expression indicates an intact MUC1 pathway and is related to functional differentiation and good prognosis, while nonapical aberrant patterns of MUC1 expression indicate a defective MUC1 pathway and are related to loss of functional differentiation and poor prognosis [15]. It was also reported that membrano-cytoplasmic expression of MUC1 was associated with histological grade 3, estrogen receptor negativity, shorter disease-free interval, and poor survival time in breast cancer [6]. Drawing comparisons between that study and the current study may be difficult because they examined the overall expression in breast cancer cases, whereas we specifically stud- ied MC. Previous studies of MC did not report different expression patterns according to type A and type B $[7,16$, 17]. Since there are no differences in prognosis between MC type A and B [11], it is difficult to assume that different subcellular localization patterns of MUC1 expression are related to MC prognosis. In this study, we found different subcellular localization patterns of MUC1 expression in breast mucinous lesions. MC type A and MLL showed luminal/apical or luminal/apical + cytoplasmic expression while MC type B and SPCs showed membrano-cytoplasmic expression. This result suggests that $\mathrm{MC}$ type A/MLL and MC type B/SPC have similar MUC1 phenotypes. 


\begin{tabular}{|c|c|c|c|c|c|c|c|}
\hline \multicolumn{3}{|c|}{ MUC5AC expression } & \multirow[t]{2}{*}{$\mathrm{p}$ value } & \multicolumn{3}{|c|}{ MUC5B expression } & \multirow[t]{2}{*}{$\mathrm{p}$ value } \\
\hline $\begin{array}{l}\text { no expression } \\
(\mathrm{n}=72)\end{array}$ & $\begin{array}{l}\text { LA or LAC } \\
(\mathrm{n}=1)\end{array}$ & $\begin{array}{l}\mathrm{CM} \\
(\mathrm{n}=5)\end{array}$ & & $\begin{array}{l}\text { no expression } \\
(\mathrm{n}=58)\end{array}$ & $\begin{array}{l}\text { LA or LAC } \\
(\mathrm{n}=1)\end{array}$ & $\begin{array}{l}\mathrm{CM} \\
(\mathrm{n}=19)\end{array}$ & \\
\hline \multirow[t]{2}{*}{$2.1 \pm 1.1$} & $3.0 \pm 0.0$ & $3.0 \pm 1.7$ & 0.226 & $2.2 \pm 1.3$ & $1.8 \pm 0.0$ & $2.1 \pm 0.5$ & 0.871 \\
\hline & & & 0.799 & & & & 0.150 \\
\hline 53 & 1 & 4 & & 46 & 1 & 11 & \\
\hline \multirow[t]{2}{*}{19} & 0 & 1 & & 12 & 0 & 8 & \\
\hline & & & 0.085 & & & & 0.320 \\
\hline 42 & 0 & 5 & & 37 & 1 & 9 & \\
\hline \multirow[t]{2}{*}{30} & 1 & 0 & & 21 & 0 & 10 & \\
\hline & & & 0.162 & & & & 0.138 \\
\hline 64 & 1 & 3 & & 48 & 1 & 19 & \\
\hline \multirow[t]{2}{*}{8} & 0 & 2 & & 10 & 0 & 0 & \\
\hline & & & 0.604 & & & & 0.216 \\
\hline 55 & 1 & 3 & & 41 & 1 & 17 & \\
\hline 17 & 0 & 2 & & 17 & 0 & 2 & \\
\hline \multirow[t]{2}{*}{14} & 0 & 2 & 0.479 & 13 & 0 & 3 & 0.724 \\
\hline & & & 0.042 & & & & 0.759 \\
\hline 67 & 1 & 3 & & 52 & 1 & 18 & \\
\hline \multirow[t]{2}{*}{5} & 0 & 2 & & 6 & 0 & 1 & \\
\hline & & & 0.166 & & & & 0.715 \\
\hline 55 & 0 & 3 & & 42 & 1 & 15 & \\
\hline 17 & 1 & 2 & & 16 & 0 & 4 & \\
\hline & & & 0.593 & & & & 0.872 \\
\hline 62 & 1 & 3 & & 49 & 1 & 16 & \\
\hline 6 & 0 & 1 & & 6 & 0 & 1 & \\
\hline 4 & 0 & 1 & & 3 & 0 & 2 & \\
\hline 4 & 0 & 1 & 0.428 & 3 & 0 & 2 & 0.686 \\
\hline
\end{tabular}

MUC2 expression was found in $92.3 \%$ of the MC cases in this study, and previous studies reported a similar result $(94-100 \%$ expression) $[7,16,17]$. However, these previous studies did not report MUC2 expression of MC type A and type B separately. In our study, different subcellular localization patterns of MUC2 expression were identified according to the type of MC. Luminal/apical or luminal/apical + cytoplasmic expression was observed in type A MCs and membrano-cytoplasmic expression was seen in type B MCs $(\mathrm{p}<0.001)$. In SPC, $53.8 \%$ of the cases were MUC2 negative, but all the MUC2-positive cases showed membrano-cytoplasmic expression similar to that seen in type B MCs. A previous study reported that MUC2 expression is higher in MC than in IDC [7]. As
MUC2 is a gel-forming mucin that works as a barrier preventing the extension of malignant tumor cells, MUC2 expression in $\mathrm{MC}$ is partially responsible for the less aggressive behavior of MC compared to IDC [7]. We found that MUC2 negativity was related to larger tumor size $(\mathrm{p}=0.011)$ and higher histological grade $(\mathrm{p}=0.007)$ in MC. The relationship between MUC2 negativity and large tumor size is consistent with gel-forming MUC2 mucin working as a barrier to tumor extension. While MUC2 negativity is related to aggressive tumor features in MC, MUC2 overexpression is related to aggressive tumor behavior in IDC $[6,18,19]$. The MLL cases were mostly negative in terms of MUC2 expression, but more MUC2 expression was observed as MLL progressed to 
MLL with ADH and MLL with DCIS ( $\mathrm{p}=0.098$ ). This finding may suggest the involvement of MUC2 in breast mucinous tumorigenesis.

To our knowledge, published studies of MUC5B expression in MC are scarce. In this study, membrano-cytoplasmic MUC5B expression was found more frequently in MC type B and in SPC than in other mucinous lesions $(\mathrm{p}=0.011)$. A previous study reported that MUC5B was expressed in $81 \%$ of breast cancers [20]. The authors suggested a correlation between MUC5B and less aggressive breast cancer based on the following findings [20]. First, the patients showing MUC5B expression in bone marrow samples had a good prognosis. Second, MUC5B intensity was lower in metastatic tumor cells in the lymph nodes than in primary breast cancer. However, in our study, a relationship between MUC5B expression in MC and clinicopathological factors was not observed. In another previous study, MUC5B was not expressed in normal breast tissues, while it was expressed in IDC, DCIS and non-malignant breast tissues in breast cancer, which suggested that MUC5B expression is an early event in the process of human breast carcinogenesis [21]. We found that MUC5B was mostly negative in MLL, but it became positive with progression to MLL with ADH and MLL with DCIS ( $p=0.022)$, suggesting that MUC5B expression is indeed an early event in mucinous breast cancer development.

In this study, the similarities in MUC1, MUC2 and MUC5B expression patterns were observed between MLL and MC type A and between MC type B and SPC. It has been suggested that MLL and MC are the pathological continuum from the following findings. First, MLL occasionally accompanies ADH and DCIS $[1,3]$. Second, the most invasive cancer accompanied by MLL is MC [22]. Third, mucin in MLL is neutral and nonsulfated acidic mucin, which is identical to that in MC [3]. Fourth, MC accompanies MLL [4]. These prior findings, in conjunction with ours, indicate that MC type A is related to MLL rather than MC type B. In addition, SPC is suggested to be a precursor of MC because SPCs occasionally secrete exteravasated mucin and accompany MC $[12,13]$. Combined with these previous studies and our results, we can also suggest that SPC is related to MC type B rather than to MC type A. Furthermore, the neuroendocrine features and cellular solid nest architecture similar to MC type B were observed in SPCs in previous studies [12, 13] as well as in this study.

In conclusion, similar MUC1, MUC2 and MUC5B expression patterns were observed between MLL and MC type A and between MC type B and SPC.

\section{Acknowledgement}

This study was supported by a faculty research grant from Yonsei University College of Medicine for 2011 (6-2011-0083).

\section{References}

1 Weaver MG, Abdul-Karim FW, al-Kaisi N: Mucinous lesions of the breast. A pathological continuum. Pathol Res Pract 1993;189: 873-876.

12 Renshaw AA: Can mucinous lesions of the breast be reliably diagnosed by core needle biopsy? Am J Clin Pathol 2002;118:82-84

-3 Ro JY, Sneige N, Sahin AA, Silva EG, del Junco GW, Ayala AG: Mucocele-like tumor of the breast associated with atypical ductal hyperplasia or mucinous carcinoma. A clinicopathologic study of seven cases. Arch Pathol Lab Med 1991;115:137-140.

-4 Chinyama CN, Davies JD: Mammary mucinous lesions: congeners, prevalence and important pathological associations. Histopathology 1996;29:533-539.

5 Fowler J, Vinall L, Swallow D: Polymorphism of the human MUC genes. Front Biosci 2001;6:D1207-D1215.
Rakha EA, Boyce RW, Abd El-Rehim D, Kurien T, Green AR, Paish EC, Robertson JF, Ellis IO: Expression of mucins (MUC1, MUC2, MUC3, MUC4, MUC5AC and MUC6) and their prognostic significance in human breast cancer. Mod Pathol 2005;18: 1295-1304.

7 Matsukita S, Nomoto M, Kitajima S, Tanaka S, Goto M, Irimura T, Kim YS, Sato E, Yonezawa S: Expression of mucins (MUC1, MUC2, MUC5AC and MUC6) in mucinous carcinoma of the breast: comparison with invasive ductal carcinoma. Histopathology 2003;42:26-36.

8 Clayton F: Pure mucinous carcinomas of breast: morphologic features and prognostic correlates. Hum Pathol 1986;17:34-38.

$\checkmark$ Norris HJ, Taylor HB: Prognosis of mucinous (gelatinous) carcinoma of the breast. Cancer 1965;18:879-885.
10 Rasmussen BB, Rose C, Christensen IB: Prognostic factors in primary mucinous breast carcinoma. Am J Clin Pathol 1987;87: 155-160.

11 Capella C, Eusebi V, Mann B, Azzopardi JG: Endocrine differentiation in mucoid carcinoma of the breast. Histopathology 1980;4: 613-630.

12 Nassar H, Qureshi H, Volkanadsay N, Visscher D: Clinicopathologic analysis of solid papillary carcinoma of the breast and associated invasive carcinomas. Am J Surg Pathol 2006;30:501-507.

$\checkmark 13$ Maluf HM, Koerner FC: Solid papillary carcinoma of the breast. A form of intraductal carcinoma with endocrine differentiation frequently associated with mucinous carcinoma. Am J Surg Pathol 1995;19:1237-1244. 
14 Elston CW, Ellis IO: Pathological prognostic factors in breast cancer. 1. The value of histological grade in breast cancer: experience from a large study with long-term follow-up. Histopathology 1991;19:403-410.

15 Rahn JJ, Dabbagh L, Pasdar M, Hugh JC: The importance of MUC1 cellular localization in patients with breast carcinoma: an immunohistologic study of 71 patients and review of the literature. Cancer 2001;91:1973-1982.

-16 Adsay NV, Merati K, Nassar H, Shia J, Sarkar F, Pierson CR, Cheng JD, Visscher DW, Hruban RH, Klimstra DS: Pathogenesis of colloid (pure mucinous) carcinoma of exocrine organs: coupling of gel-forming mucin (MUC2) production with altered cell polarity and abnormal cell-stroma interaction may be the key factor in the morphogenesis and indolent behavior of colloid carcinoma in the breast and pancreas. Am J Surg Pathol 2003;27:571-578.
17 Chu JS, Chang KJ: Mucin expression in mucinous carcinoma and other invasive carcinomas of the breast. Cancer Lett 1999;142: 121-127.

-18 Walsh MD, McGuckin MA, Devine PL, Hohn BG, Wright RG: Expression of MUC2 epithelial mucin in breast carcinoma. J Clin Pathol 1993;46:922-925.

19 Xu Y, Kimura N, Yoshida R, Lin H, Yoshinaga $\mathrm{K}$ : Immunohistochemical study of MUC1, MUC2 and human gastric mucin in breast carcinoma: relationship with prognostic factors. Oncol Rep 2001;8:1177-1182.
20 Varangot M, Barrios E, Sonora C, Aizen B, Pressa C, Estrugo R, Lavigna R, Muse I, Osinaga E, Berois N: Clinical evaluation of a panel of mRNA markers in the detection of disseminated tumor cells in patients with operable breast cancer. Oncol Rep 2005;14: 537-545.

-21 Sonora C, Mazal D, Berois N, Buisine MP, Ubillos L, Varangot M, Barrios E, Carzoglio J, Aubert JP, Osinaga E: Immunohistochemical analysis of MUC5B apomucin expression in breast cancer and non-malignant breast tissues. J Histochem Cytochem 2006; 54:289-299.

$\checkmark 22$ Hamele-Bena D, Cranor ML, Rosen PP: Mammary mucocele-like lesions. Benign and malignant. Am J Surg Pathol 1996;20: 1081-1085. 